\title{
COVID-19 CRISIS AS A COLLECTIVE HERO'S JOURNEY TO BETTER PUBLIC AND GLOBAL MENTAL HEALTH
}

\author{
Miro Jakovljevic \\ Department of Psychiatry and Psychological Medicine, University Hospital Centre Zagreb, Zagreb, Croatia \\ $* * * * *$
}

\section{Introduction}

The COVID-19 pandemic represents very complex events, complex in its origin, its spread, its effects and its consequences at multiple levels and fields; medical, social, political, economic, religious, cultural and civilizational (Jakovljevic et al. 2020). As the human health means resilience, coherence, well-being and psychosomatic balance (Jakovljevic 2018) it is quite clear and evident that COVID-19 pandemic does not affect only somatic health, but also mental health and personal well-being (Fiorillo \& Gorwood 2020). At the moment when the humankind/our world is in the midst of COVID-19 physical pandemic and infodemic, there are massive mental health problems as possible pandemic lurking in the shadows, and nobody is immune to it at this point. Our whole world, the human race is facing with huge existential threat, the slow and unstoppable changing and possible destruction of everything that has been important for us. The worry that people have about themselves, families, wages, and work is overwhelming for millions. Hypes, half-truths and false information from some outlets in the popular media are making things worse (London 2020). All health care workers, doctors, nurses are overwhelmed. We must address the mental health of our colleagues and communities and start working on it quickly and efficiently.

The present COVID-19 pandemic has raised a number of questions about the importance and roles of psychiatry and mental health sciences in medicine and society. Transdisiplinary integrative psychiatry has been devoted to the three missions: 1. to study, diagnose, treat and prevent mental disorders; 2 . to help other branches of medicine to be more successful and to promote person-centered medicine through practice of the consultation-liaison psychiatry; and 3. to promote public and global mental health and the concepts of compassionate society and empathic civilization (Jakovljevic 2017, 2018).

\section{COVID-19 and pandemic of mental disorders}

The COVID-19 pandemic is not only medical issue, because it affects individuals, families, societies and the global world on many levels causing many disruptions associated with different mental, cognitive, emotional and behavioral responses and disorders. First we had had COVID-19 epidemic, than we have had pandemic and infodemic, but we should be ahead of the simmering mental health crisis before it boils over and explode. Sudden and unexpected changing of the orientation to the world and worldviews, routine and established way of life (critical "stay at home" and "quarantine" period), individual and community communication and conducting at work and home without a deadline when this pass over is a huge challenge and shock for many people. The fear of uncertainty, death, loss of job, drastic changes of life styles, isolation, physical distancing, separation from family and friends, stigmatization, etc. are related to high level mental risks. The touching things, being with and hugging other human beings, shaking hands and breathing the air with them in the same place can be dangerous. Distress and traumatic experience, over-reactions and maladaptive defense mechanisms (see Marcinko et al. 2020) which differ from person to person may trigger different mental disorders, such as anxiety and depressive disorders, post-traumatic stress disorder, obsessive-compulsive disorder, etc. Mentally we have been passing through different stages: denial, anger, bargaining, depression, and acceptance (Hamdani 2020). Denial when people refuse to acknowledge the threatening reality is presented particularly at the beginning of crisis. Some are angry and sad because of losing free choices what to do, social and cultural events, celebrations, graduations, concerts, sport's manifestations, etc. Some are already bargaining and accepting the changes by adapting technology to wait this out until coming out on the other side. Psychiatrists can educate and promote methods and interventions that foster positive behavioral change and solidarity. Focus on life-style medicine and psychiatry encouraging people to hope, pray, sing, dance, exercise, and use relaxation techniques to restart their brains and control their stress, anxiety, worry, and PTSD may be very efficient. These simple actions can induce in our mind and body relaxation, calmness, peace, mindfulness and strengthen resilience.

\section{COVID-19 pandemic and the role of consultation-liaison psychiatry}

COVID-19 represents a new challenge for consultation- liaison psychiatry. It offers mental health support to both patients with comorbidity and medical staff who treats them. Many hospitals, including the psychiatric departments and hospitals, announced that non-essential 
staff can stay at home and eventually practice telemedicine, but without specific instructions. There are reports about some psychiatrists who have expressed guilt about the ability to see patients via tele-health while inpatient and emergency room physicians continue to see patients in person (see Allen \& Mishkin 2020). Treating persons who are struggling with fear and uncertainty related to the pandemic, persons not physically ill but quarantined or in self-isolation at home even if they are not infected with coronavirus are essential and necessary. Coronavirus panic attack with symptoms such as hard to catch breath, chest pain and fear of dying may be confused for the symptoms of respiratory distress in COVID-19 (Onyemaechi 2020). Recognizing such patients can prevent many problems. Liaison psychiatrists have an essential role to help health-care workers who treat COVID-19 patients, and commonly work within prolonged working-time and insufficient personal protective equipment, separated from their families and in fear for them, with increased rates of patient loss, and in some case stressed to triage access to ventilators. More and more health care workers treating COVID-patients will inevitably struggle with the impact of the crisis for the foreseeable future (Allen \& Mishkin 2020). An easy available and highly professional mental health support for all frontline health care workers should be an important task and ethical duty of all health care systems.

\section{COVID-19 pandemic as a collective hero's journey to compassionate society and empathic civilization}

According Joseph Campbel, American mythologist the hero's journey in narratology is the common framework of a broad category of tales, myths and lores in which hero goes on an adventure, enters the darkness, faces adversity, and in a decisive crisis wins a victory and retrieves the treasure and comes home changed and transformed (see Gilligan \& Dilts 2009). Each life is hero's journey which is about living gifts and healing wounds, when we enter the darkness we retrieve the treasures that exist within us like an inner power, strength, love, wisdom, meaning and purpose that are gifts we have to offer to the world and come to the light. Transformed by a hero's journey individually and collectively we spiritually grow in being able to live the truth that hurtfulness and happiness can coexist around and within us and create the world of love, compassion and empathy inwardly and outwardly. The COVID-19 has changed our world, the period of ease is transformed into crisis and we are being challenged to become the better version of ourselves and activate and create our Generative Self and new resources. Experiences of pain, loss, dichotomies, polarities, and contradictions are an inevitable part of our world and we can all learn to trust our capacity to enter the darkness of pandemic and go out to the light of a new compassionate society and the dawn of empathic civilization. Wise navigating the hero's journey through the COVID-19 pandemic gives us the challenging opportunity to discover that we are more powerful and successful when we are united and empathic than when we are selfish and narcissistic. The COVID-19 hero's journey helps us to know better who we are as a humankind and what we should value. Now it is quite clear that many rules we have lived under were wrong and unnecessary, and made our world fragile, selfish and disunite. New ideas about understanding patriotism more as cultivating the life and community health, of course involving mental health too, has appeared. Public health politics as well as politics in general should be matter for more serious, responsible, moral, wise and educated people. Hyper-globalization in the interest of big corporations, culture of hyper-individualism, selfish market society and multi/polarization of our world do not promise light future and may lead to the dystopian scenario. From the public and global mental health we are to recognize a fundamental fact that we are a species that has evolved to thrive on love, empathy and compassion associated with our cooperation, interconnectedness and interdependency (Jakovljevic 2017). Education for resilience and anti-fragility, love, empathy and cooperation while fighting the COVID-19 pandemic may contribute to the building of compassionate societies and empathic civilization (Jakovljevic et al. 2020).

\section{Conclusions}

The world is in the midst of the COVID-19 pandemic, emerging huge global geopolitical changes and possibly pandemic of mental disorders. The position of psychiatry within the medicine and society is evolving from time to time. As it is to be expected that there will be a range of long-term negative mental health consequences to this pandemic, psychiatrists and other mental health workers are to help their patients, their families, and the whole community to better understand and prevent mental health problems' pandemic. Let's hope that the war against corona disease will be followed by more successful fighting for public and global mental health with more agility

\section{Acknowledgements: None.}

\section{Conflict of interest: None to declare.}

\section{References}

1. Allen $N$ \& Mishkin AD: Being essential in the time of COVID-19. Psychiatric Times March 30, 2020

2. Fiorillo $A \&$ \& Goewood P: Fiorillo A \& Gorwood P: The consequencies of the COVID-19 pandemic on mental health and implications for clinical practice. Editorial. European Psychiatry, April 2020, pp. 1-4. DOI: https://doi.org/10.1192/eurpsy.2020.35 
3. Gilligan $S$ \& Dilts R: The Hero's Journey: A Voyage of Self Discovery. Crown House Publishing Limited, UK 2009

4. Hamdani NF: The next pandemic will be in mental health. kevin.com/blog/202. March 25, 2020

5. Jakovljevic M: Resilience, psychiatry and religion from public and global mental health promotion. Psychiatr Danub 2017; 29:238-244 https://doi.org/10.24869/psyd/2017.238

6. Jakovljevic M: Empathy, sense of coherence and resilience: bridging personal, public and global mental health and conceptual synthesis. Psychiatr Danub 2018; 30:380-384

7. Jakovljevic $M$, Bjedov $S$, Jaksic $N$ \& Jakovljevic I: COVID-19 pandemia and public and global mental health from the perspective of global health security. Psychiatr Danub 2020; 32:6-14
8. London R: Is COVID-19 leading to a mental illness pandemic? Medscape April 03, 2020

9. Marcinko D, Jakovljevic M, Jaksic N, Bjedov $S$ \& Mindoljevic Drakulic A: The importance of psychodynamic approach during COVID-19 pandemic. Psychiatr Danub 2020; 32:14-20

10. Onywmaechi $C$ : Redefining the role of psychiatrists in the time of COVID-19. MEDPAGE TODAY'S April 3, 2020 kevinmd-com

11. Schwartz A: The Post-Traumatic Growrh GuidebookPractical Mind-Body Tool to Heal Trauma, Foster Resilience and Awaken Your Potential

12. Schwartz A: Covid-19: A Collective Hero's Journey, March 28, 2020 https://drarielleschwartz.com

Correspondence:

Professor Miro Jakovljevic, MD, PhD

Department of Psychiatry and Psychological Medicine,

University Hospital Centre Zagreb

Kišpatićeva 12, 10000 Zagreb, Croatia

E-mail: psychiatry@kbc-zagreb.hr 